Original article

\title{
IMPACT OF ACQUISITION PARAMETERS ON THE QUANTITATIVE ASSESSMENT OF PET IMAGING - ANALYSIS OF THE NEMA PHANTOM
}

\author{
VPLIV SLIKOVNIH PARAMETROV NA KVANTITATIVNO OCENO PET SLIKE - \\ ANALIZA FANTOMA NEMA
}

\author{
Sebastijan Rep \\ *Corresponding author: sebastijan.rep@guset.arnes.si \\ Received: 7. 4. 2020 \\ Accepted: 25.7 .2020 \\ https://doi.org/10.47724/MIRTJ.2020.i01.a005
}

University Medical Centre Ljubljana, Clinic of Nuclear medicine, Zaloška 7, 1000 Ljubljana, Slovenia

\begin{abstract}
Aim: The aim of the research was to analyse the most common factors that influence SUV values.

Material and methods: In the study, I used a NEMA body phantom filled with a mixture of water and $18 \mathrm{~F}-\mathrm{FDG}$ in a ratio 1:4 (background/spheres), and analysed the most common factors that influence SUV values. The most common factors include the impact of the patient's body weight, the impact of time between application and PET/CT imaging, and the impact of differently prepared and administered RP activities.

Results: Different values of patient body weight, time between application and PET/CT imaging, and differently prepared and administered RF activities have a statistically significant effect on the quantitative assessment of SUVmax $(p<0.001)$ and SUVmean $(p<0.001)$.
\end{abstract}

Conclusion: The results showed that all factors can significantly influence the quantitative assessment of SUVmax and SUVmean.

Keywords: PET/CT, quantitative assessment, SUVmax, SUVmean, body weight

\section{IZVLEČEK}

Namen: Analizirati najpogostejše dejavnike, ki vplivajo na vrednosti SUV.

Materiali in metode: $V$ raziskavi sem uporabil fantom NEMA, napolnjen z mešanico vode in 18F-FDG v razmerju 1:4 (ozadje/ sfere) in analiziral najpogostejše dejavnike, ki vplivajo na vrednost SUV. Najpogostejši dejavniki vključujejo vpliv telesne teže pacienta, vpliv časa med aplikacijo in slikanjem s PET/ CT in vpliv različno pripravljene in aplicirane koncentracije aktivnosti radiofarmaka (RF).

Rezultati: Različne vrednosti telesne teže pacienta, čas med aplikacijo in slikanje s PET/CT in različno pripravljene in aplicirane koncentracije aktivnosti RF statistično pomembno vplivajo na kvantitativno oceno SUVmax ( $p<0,001$ in SUVmean $(p<0,001)$.

Zaključek: Rezultati so pokazali, da lahko vsi dejavniki pomembno vplivajo na kvantitativno oceno SUVmax in SUVmean.

Ključne besede: PET/CT, kvantitativna ocena, SUVmax, SUVmean, telesna teža 


\section{INTRODUCTION}

Positron emission tomography (PET) in combination with computed tomography (CT) is a hybrid imaging diagnostic method that is frequently used for diagnosis, prognosis and monitoring response to oncological therapy. The hybrid system facilitates a parallel anatomical image using computed tomography (CT) and functional image using PET. Visual assessment is the main tool for image interpretation in clinical practice. Although visual assessment may be sufficient to evaluate tumour response, a precise assessment of tumour response to therapy requires a certain form of quantification $(1,2)$. PET is a diagnostic imaging method that facilitates the quantitative assessment of the pathological process. The quantitative assessment enables objective and precise evaluation to predict and monitor therapeutic response so that it does not depend solely on the visual imaging assessment. Quantification in PET examinations represents an accumulated amount of radiopharmaceuticals (RP) inside the tumour and facilitates a precise division into groups of patients who experience therapeutic response and those who do not $(3,4)$. A quantitative analysis utilising $18 \mathrm{~F}$ - fluorodeoxyglucose (18F-FDG) in the assessment of early therapeutic response increased the role of PET in drug development in oncology (5). Standardised uptake value (SUV) is a simplified quantitative assessment and the most frequently used method to assess accumulation of 18F-FDG PET in examinations $(6,7)$.

SUV is a number that stands for the accumulation activity of $\mathrm{RF}$ inside the tumour or the entire body that was measured after intravenous RP application in a predetermined period. SUV is normalised to the applied RF dose and factor that takes into account the distribution of RF in the whole body $(8,9)$. The most common factors for normalisation of RF distribution in the whole body are body weight (BW) and body surface area (BSA). Patients who undergo an 18F-FDG exam must do so on an empty stomach. Those patients have a decreased RP accumulation in the fat, which can impact body weight, and therefore, a method considering lean body mass (LBM) is used. LBM is defined as the difference between total body mass and body fat, and takes into account the mass of all organs, excluding body fat. The use of LBM for the normalisation of SUV is more appropriate for heavier patients than BW or BSA $(10,11)$.

Physiological and technical factors or factors that are the result of human error impact the results of the highest concentration activity (SUVmax) and average concentration activity (SUVmean). A common technical error that impacts SUV is a discrepancy in time at PET/CT and dose meter. To avoid an incorrect SUV, time on a dose meter and PET/CT should be checked daily. Data collection period is an image parameter that impacts the signal-to-noise ratio (SNR) and consequently SUV. Along with the processing parameters, SUV is also impacted by the selection of the matrix element (due to the effect of partial volume), reconstruction algorithm and normalisation factor. SUV is also dependent on the region of interest (ROI), the selection of which is impacted by the individual's choice. Most common factors that impact SUV are shown in Table $1(8,12-14)$.
Table 1: Most common factors that impact the quantitative assessment of a PET image

\begin{tabular}{|c|c|c|}
\hline CAUSE & FACTOR & EXPLANATION \\
\hline \multirow[t]{2}{*}{$\begin{array}{l}\text { Technical } \\
\text { error }\end{array}$} & $\begin{array}{l}\text { Incorrect time } \\
\text { synchronisation } \\
\text { between PET/CT and } \\
\text { dose meter }\end{array}$ & $\begin{array}{l}\text { Incorrect SUV due to } \\
\text { erroneous correction of } \\
\text { RP decay }\end{array}$ \\
\hline & $\begin{array}{l}\text { Paravenous } \\
\text { application of } \\
\text { 18F-FDG }\end{array}$ & $\begin{array}{l}\text { Amount of applied RF } \\
\text { is decreased, resulting } \\
\text { into incorrect SUV }\end{array}$ \\
\hline \multirow[t]{4}{*}{$\begin{array}{l}\text { Physical } \\
\text { factors }\end{array}$} & Imaging parameters & $\begin{array}{l}\text { Low SNR value causes a } \\
\text { biased SUV }\end{array}$ \\
\hline & $\begin{array}{l}\text { Reconstruction } \\
\text { parameters }\end{array}$ & $\begin{array}{l}\text { Partial volume effect on } \\
\text { SUV }\end{array}$ \\
\hline & Selection of ROI & $\begin{array}{l}\text { SUV result is highly } \\
\text { dependent on the } \\
\text { selection of ROI size }\end{array}$ \\
\hline & $\begin{array}{l}\text { Normalisation factor } \\
\text { for SUV }\end{array}$ & $\begin{array}{l}\text { SUV depends on weight, } \\
\text { body surface and other } \\
\text { normalisation factors for } \\
\text { the calculation of SUV }\end{array}$ \\
\hline
\end{tabular}

\section{AIM}

The aim of the study was to demonstrate and analyse the most common factors that impact SUVmax and SUVmean values. The following factors were included in the analysis:

- impact of patient's body weight,

- impact of time between the application and data collection with PET/CT, and

- impact of differently prepared and applied RF concentration activity.

\section{METHODS}

A NEMA body phantom was used to analyse factors that impact the quantitative assessment of SUV (SUVmax/mean). I conducted the phantom imaging on a SIEMENS hybrid system, Biograph $\mathrm{mCT}^{\circledast} 128 \mathrm{PET} / \mathrm{CT}$, which combines a 128-slice CT and LSO PET detector system with three rings. The phantom volume was 9.7 litres and consisted of six hollow spheres with diameters of $37,28,22,17,13$ and $10 \mathrm{~mm}$. The phantom was filled with a mixture of water and 18F-FDG in a 1:4 ratio (background/sphere). When performing the PET/CT imaging, I collected the $\mathrm{CT}$ data for attenuation correction first, then the PET data with the application of a single bed position. For the reconstruction of data, I used the iterative reconstruction algorithm (TrueX + TOF) that encompasses the point spread function (PSF) and time-of-flight information (TOF). SUV is most frequently normalised to body weight (BW) and is calculated using the following formula (Formula 1):

$\operatorname{SUV}_{B W}=\frac{A C v o i(M B q / m l)}{F D G d o s e(M B q) / B W(k g)} \quad$ Formula 1

In Formula 1, ACvoi represents the average or highest activity concentration expressed in $\mathrm{MBq} / \mathrm{ml}$, in a defined region of 
interest (ROI). FDGdose represents the dose of FDG expressed in megabequerels $(\mathrm{MBq})$, while body weight (BW) is expressed in kilograms.

SUV corrected to LBM is calculated using Formula 2:

$\operatorname{SUV}_{L B W}=\frac{A C v o i(M B q / m l)}{F D G d o s e(M B Q) / L B M(k g)} \quad$ Formula 2

ACvoi represents the average or highest activity concentration expressed in $\mathrm{MBq} / \mathrm{ml}$, in a defined region of interest (ROI). FDGdose represents the dose of FDG expressed in MBq. LBM value depends on the gender, body weight and height of a patient, and is calculated differently for men and women. LBM (women) $=(1.07 \mathrm{x}$ body weight) $(\mathrm{kg})-148$ [body weight $(\mathrm{kg}) /$ body height $(\mathrm{cm})]^{2}$ and LBM (men) $=(1.1 \mathrm{x}$ body weight) $(\mathrm{kg})$ 128 [body weight $(\mathrm{kg}) /$ body height $(\mathrm{cm})]^{2}(15)$.

SUV corrected to BSA is calculated using Formula 3:

$\operatorname{SUV}_{B S A}=\frac{A C v o i(M B q / m l)}{F D G d o s e(M B q) / B S A\left(m^{2}\right)} \quad$ Formula 3

ACvoi represents the average or highest activity concentration expressed in $\mathrm{MBq} / \mathrm{ml}$, in a defined region of interest (ROI). FDGdose represents the dose of FDG expressed in MBq. The height and weight of patients must be entered in the imaging or processing protocol to calculate BSA. The entered data are applied to calculate BSA, using the following formula:

BSA $\left(\mathrm{m}^{2}\right)=0.007184 \mathrm{x}$ body weight $(\mathrm{kg})^{0.425} \mathrm{x}$ body height $(\mathrm{cm})^{0.725}(16)$.

I analysed the impact of incorrectly entered body weight, RP application time and prepared RP activity on SUVmax and SUVmean on a NEMA phantom. I systematically entered data in the imaging protocol and thus simulated an error. I altered the weight of the phantom ( $10 \mathrm{~kg}$ ) by $10 \%, 20 \%, 30 \%$ and $40 \%$, and analysed SUVmax and SUVmean. In terms of time impact on SUVmax and SUVmean, I simulated an error by entering times of 1, 3, 7, 15, 30, 45 and 60 minutes. By altering activity by $5 \%$ from the reference, I calculated the impact of lower and higher activity of prepared RF on the quantitative assessment of SUVmax and SUVmean.

On the images, I marked regions of interest of approximately six spheres of different sizes in the NEMA body phantom. An analysis of obtained quantitative assessments of SUVmax/ mean was conducted using SPSS 25 software. The ShapiroWilk test was applied to assess the distribution of variables. I used the analysis of variance (ANOVA) test (repeated measures) for dependent variables in the normal distribution and the Friedman test when variables were not distributed normally. I used a $p$ value of $<0.05$ for the threshold of statistical significance.

\section{RESULTS}

An analysis of the normalisation of SUVmax and SUVmean to BW, LBM in BSA showed a statistically significant difference at SUVmax $(p=0.002)$ and at SUVmean $(p<0.001)$. The obtained SUVmax and SUVmean values are shown in Tables 2 and 3.

Table 2: SUVmax values at different sphere volumes normalised to $B W, L B M$ and $B S A$

\begin{tabular}{|c|c|c|c|}
\cline { 2 - 4 } \multicolumn{1}{c|}{} & \multicolumn{3}{c|}{ SUVmax value } \\
\hline Sphere volume & $\boldsymbol{B W}$ & LBM & BSA \\
\hline 0.5 & 2.67 & 13.97 & 0.41 \\
\hline 1.13 & 4.49 & 23.45 & 0.70 \\
\hline 2.5 & 6.07 & 31.67 & 0.94 \\
\hline 5.02 & 6.05 & 31.60 & 0.94 \\
\hline 11.01 & 5.75 & 30.05 & 0.89 \\
\hline 23.41 & 5.59 & 29.16 & 0.87 \\
\hline
\end{tabular}

Table 3: SUVmean values at different sphere volumes normalised to $B W, L B M$ and $B S A$

\begin{tabular}{|c|c|c|c|}
\cline { 2 - 4 } \multicolumn{1}{c|}{} & \multicolumn{3}{c|}{ SUVmean value } \\
\hline Sphere volume & BW & LBM & BSA \\
\hline 0.5 & 2.4 & 12.53 & 0.37 \\
\hline 1.13 & 3.15 & 16.45 & 0.47 \\
\hline 2.5 & 3.57 & 23.56 & 0.55 \\
\hline 5.02 & 4.08 & 21.08 & 0.63 \\
\hline 11.01 & 4.26 & 22.24 & 0.66 \\
\hline 23.41 & 4.57 & 23.86 & 0.71 \\
\hline
\end{tabular}

\section{Changing SUVmax values normalised to BW at different body weights}

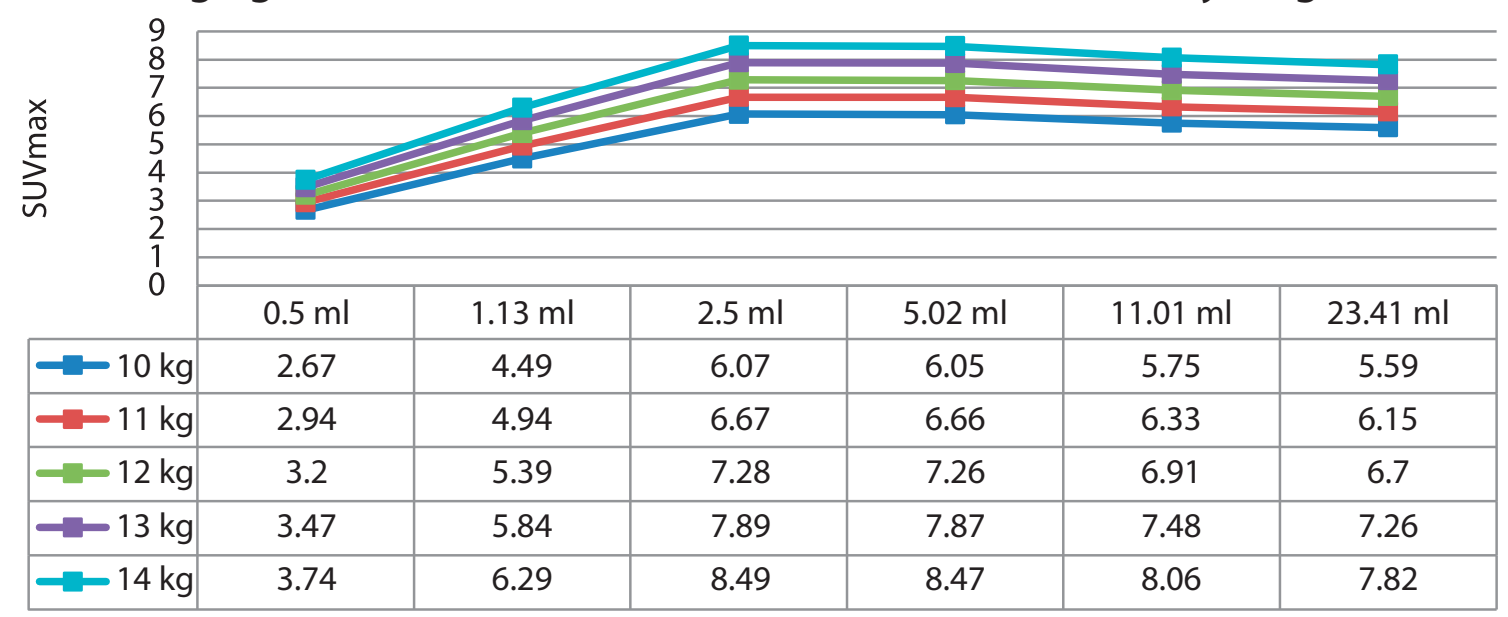

Image 1: Impact of body weight to SUVmax at different sphere volumes normalised to BW, when body weight is altered by $10 \%$ from the initial weight of the NEMA phantom (10 kg). The curves illustrate SUVmax value fluctuations at different body weights. 


\section{Changing SUVmean values normalised to BW at different body weights}

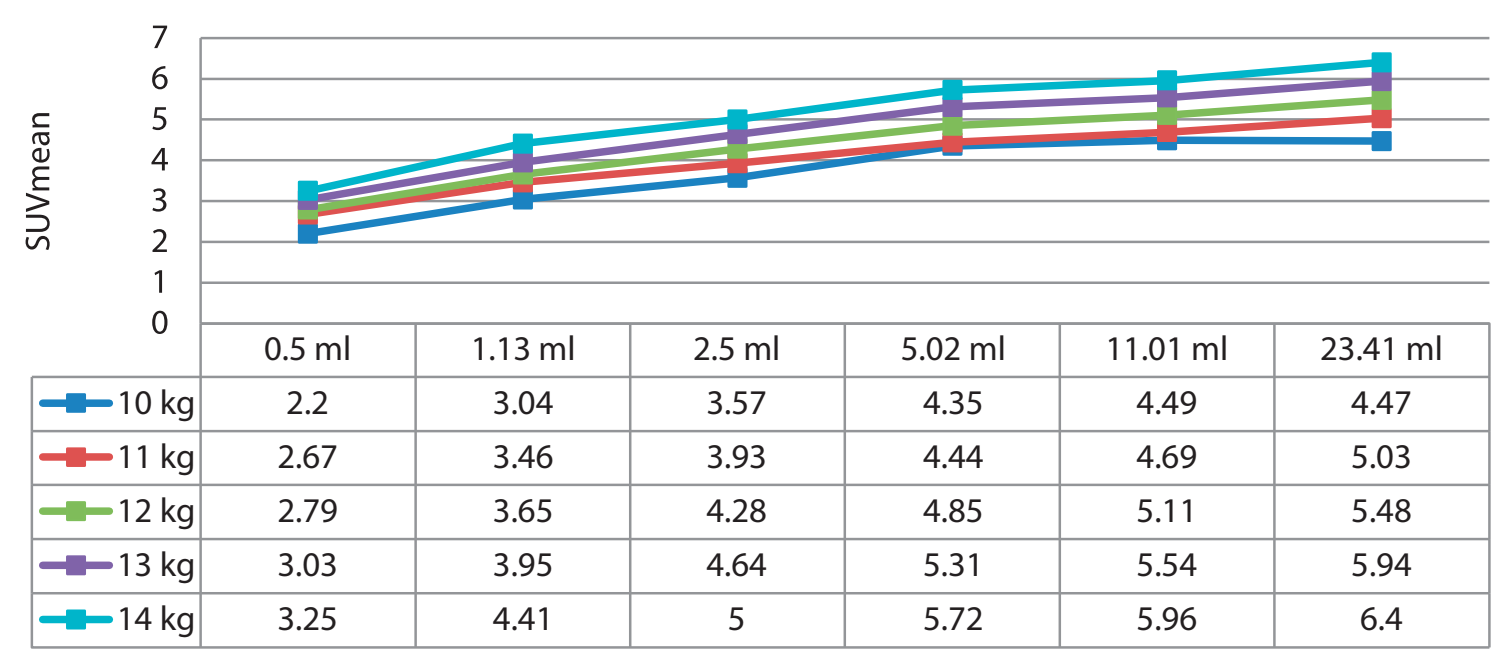

Image 2: Impact of body weight to SUVmean at different sphere volumes normalised to BW, when body weight is altered by $10 \%$ from the initial weight of the NEMA phantom $(10 \mathrm{~kg})$. The curves illustrate the SUVmean value fluctuations at different body weights.

\section{Altered SUVmax values normalised to BSA at different body weights}

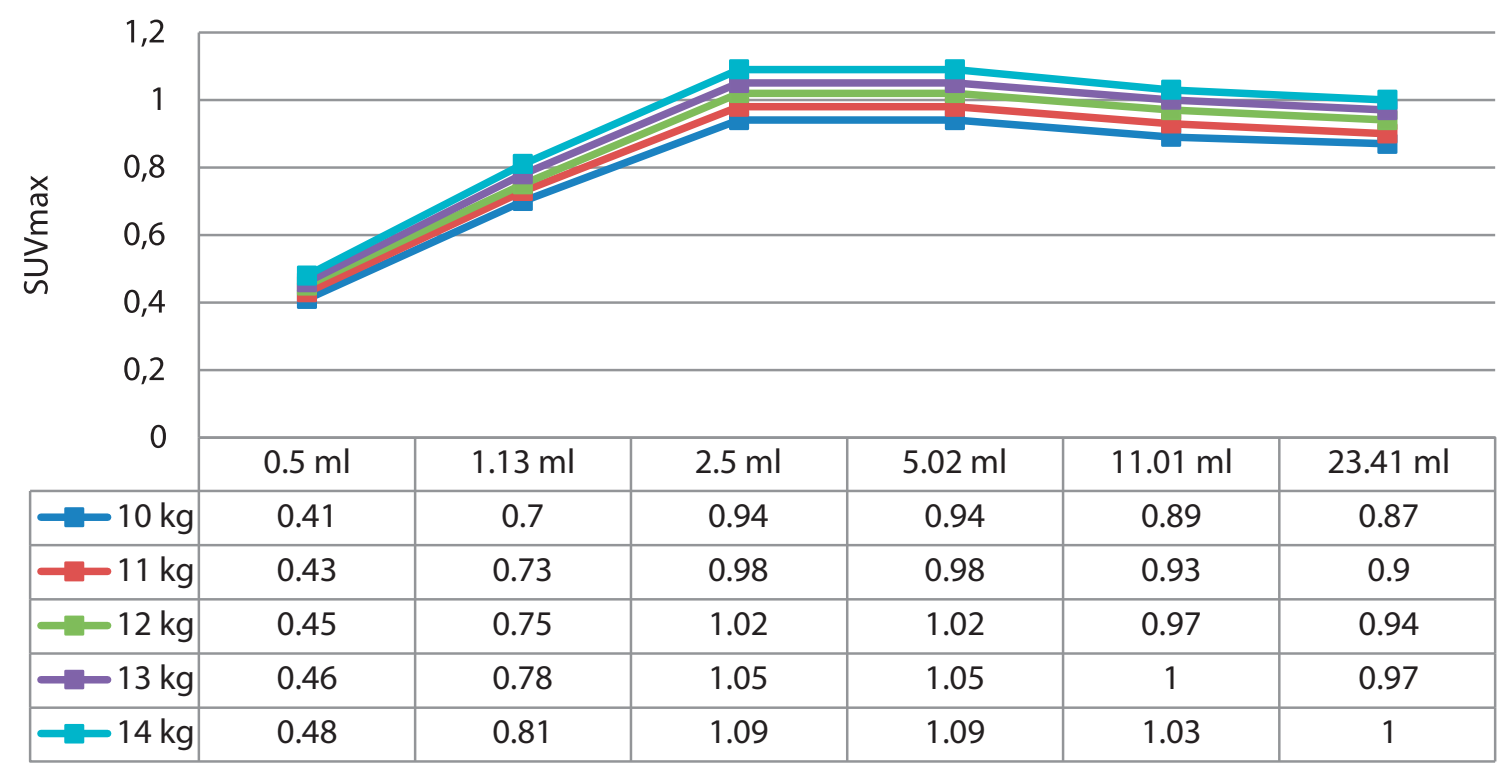

Image 3: Impact of body weight to SUVmax at different sphere volumes normalised to BSA, when body weight is altered by $10 \%$ from the initial weight of the NEMA phantom (10 kg). The curves illustrate the SUVmax value fluctuations at different body weights.

The erroneous entry of body weight can have a statistically significant impact on SUVmax $(p<0.001)$ and SUVmean $(p$ $<0.001$ ) values. Image 1 and 2 show a trend of changing SUVmax and SUVmean normalised to BW, if body weight is steadily increased by $10 \%$.

The normalisation of SUV to BSA at different body weights showed a statistically significant difference at SUVmax $(p<$ $0.001)$ and SUVmean ( $<0.001)$. Image 3 and 4 show SUVmax and SUVmean values at different body weights.

The erroneous entry of application time in the protocol or a deviation between time on the applicator and time on PET/ CT scanner showed a statistically significant difference at SUVmax $(p<0.001)$ and SUVmean $(p<0.001)$. Image 5 and 6 show deviations between different time points at SUVmax and SUVmean values.
The analysis of applied RP activity concentration showed a statistically significant difference when a 3 or more $\%$ of lower or higher intravenously RP activity concentration is applied at SUVmax $(p<0.001)$ and at SUVmean $(p<0.001)$. SUVmax and SUVmean are increasing at a lower applied activity than recommended and decreasing at higher values. Image 7 and 8 show differences in SUVmax and SUVmean values at a lower applied RP activity.

\section{DISCUSSION}

Quantitative PET/CT is an important tool for diagnosis, prognosis and monitoring the response to oncological therapy. Many factors impact the quantitative assessment of SUV PET/CT. To understand these factors, I analysed the most common factors and compared them to the results of research conducted by other authors. 


\section{Altered SUVmean values normalised to BSA at different body weights}

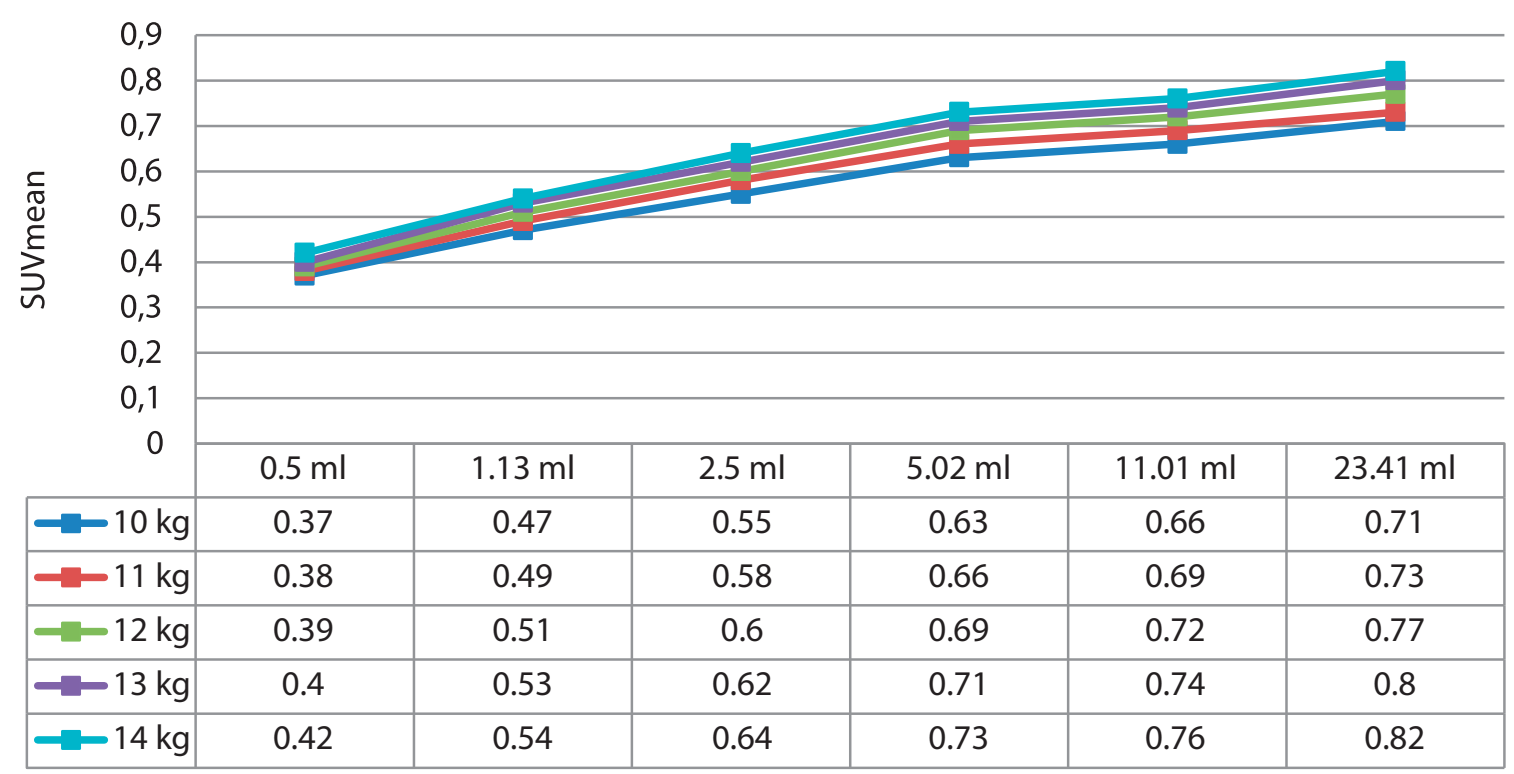

Image 4: Impact of body weight to SUVmean at different sphere volumes normalised to BSA, when body weight is altered by $10 \%$ from the initial weight of the NEMA phantom (10 kg). The curves illustrate the SUVmean value fluctuations at different body weights.

\section{SUVmax values at time deviation}

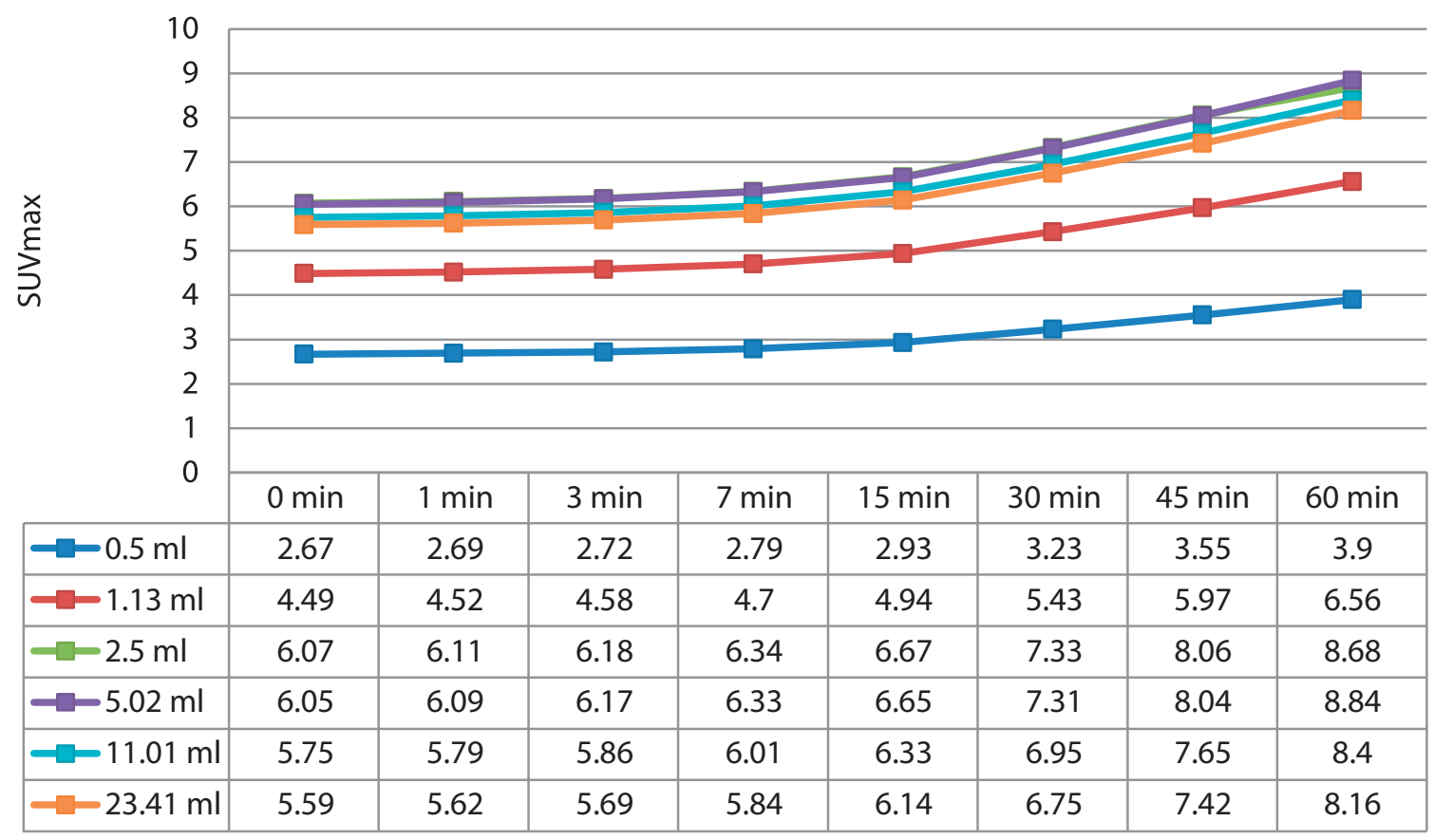

Image 5: SUVmax values at different sphere volumes and time deviations as a consequence of the erroneous entry of application time or time discrepancies between applicator and PET/CT scanner. The curves illustrate the SUVmax value fluctuations at time deviation.

SUVmax and SUVmean are primarily normalised to BW. However, normalisation factors LBM and BSA are also used. Weber et al. (3), Lammertsma et al. (17), Young et al. (18) and Boellaard et al. (19) used analyses and determined that SUVmax and SUVmean normalised to BSA could have been more appropriate in examinations, particularly when patients lose weight during therapy. I conducted this research on the NEMA body phantom and compared SUVmax and SUVmean normalised to BW, LBM and BSA, and came to the conclusion that differences in body weight can have a statistically significant impact on SUVmax and SUVmean when they are normalised to BW and BSA. The results of other authors also show the impact of lost body weight during therapy to SUV. The most appropriate method for the normalisation of SUV is still the subject of discussion and thus needs to be unified with multi-centre trials $(3,8,9,17-19)$.

Time is an important parameter that impacts the quantitative assessment of SUV. The correct calculation of SUV depends on a precise cross-calibration between the PET/CT machine and the activity/dose meter (calibrator) that is used for measuring the activity concentration of applied RP for the patient. A common problem may occur as the result of an erroneous time 


\section{SUVmean values at time deviation}

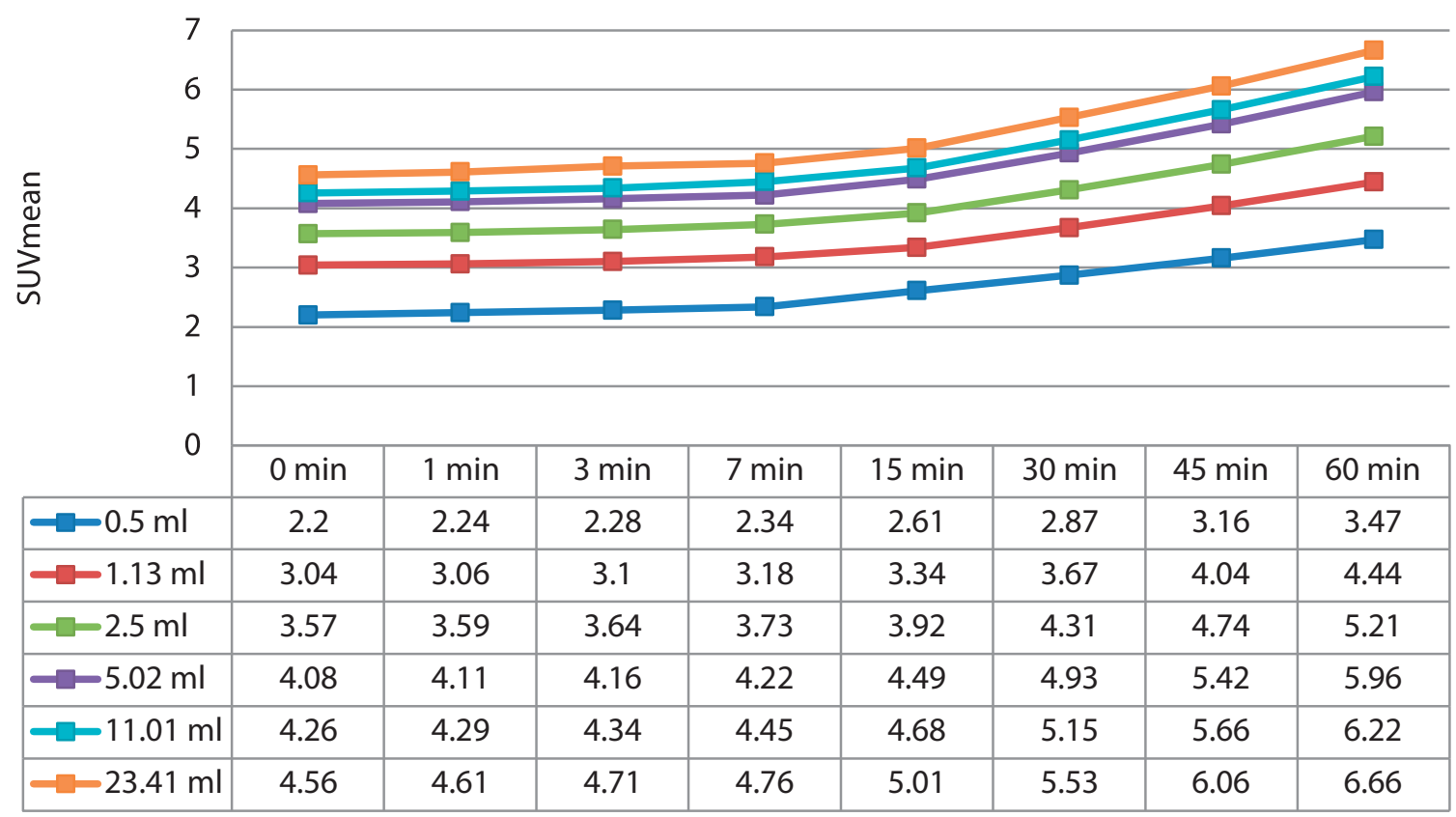

Image 6: SUVmean values at different sphere volumes and time deviations as a consequence of the erroneous entry of application time or time discrepancies between applicator and PET/CT scanner. The curves illustrate the SUVmax value fluctuations at time deviation.

\section{SUVmax values in different applied activities}

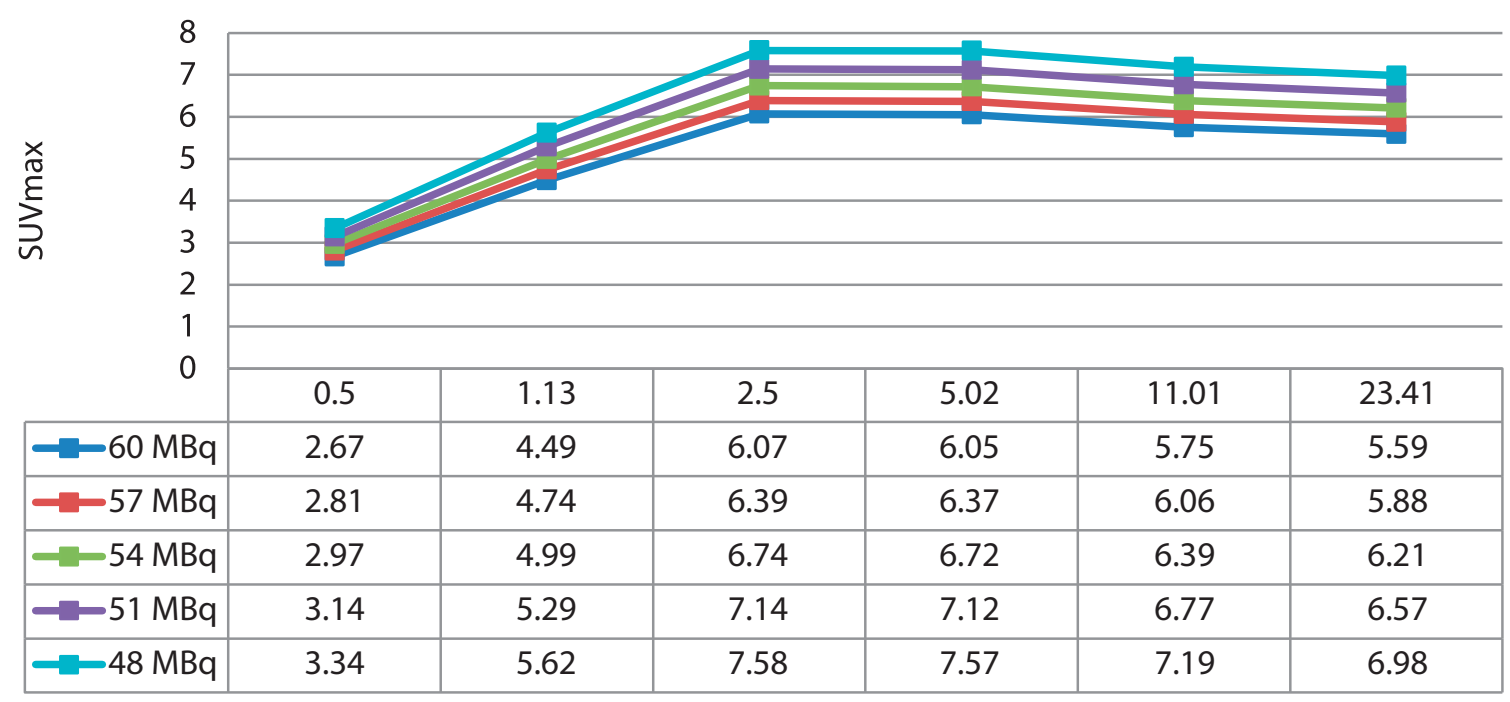

Image 7: SUVmax values of different sphere volumes and different radiopharmaceutical activities. The curves illustrate the SUVmax value fluctuations at different radiopharmaceutical activities.

synchronisation on a PET/CT scanner and time on the activity/ dose meter (calibrator) or read-out computer. RP is prepared for a patient and defined for a specific time unit, which is usually not entirely the same as the actual application time. It is therefore necessary to use the right corrections of physical decay of RP.This means that the RP activity for application must be defined on the basis of RP preparation and application, and the time when PET/CT imaging begins. The obtained analysis results confirm the impact of time on SUV. An error can be the result of erroneous time synchronisation between PET/CT and dose meter (calibrator) or a consequence of erroneous time entry in the imaging protocol. The collected results match the results of other studies $(3,12,13,19)$.
The net activity/dose of prepared RP that is administered to a patient must be measured precisely and applied in whole. It must be ensured that the remaining activity after the RP application in the injector is minimised to $1 \%$. The remaining activity in the injector can be measured after use. It is lower than $3 \%$ of the defined dose in most cases (95\%). It is necessary to know the exact net activity/dose prepared for a patient. In 5\% of all cases, the remaining activity in the injector accounts for $10 \%$ (19). This is mostly due to a very high specific RP activity (RP activity on a total amount or mass $\mathrm{MBq} / \mathrm{ml}$ ), i.e. soon after production). To avoid this, the empty volume in the injector and the application process must be taken into account. The aforementioned problems can arise when RP is prepared and 


\section{SUVmean in different applied activities}

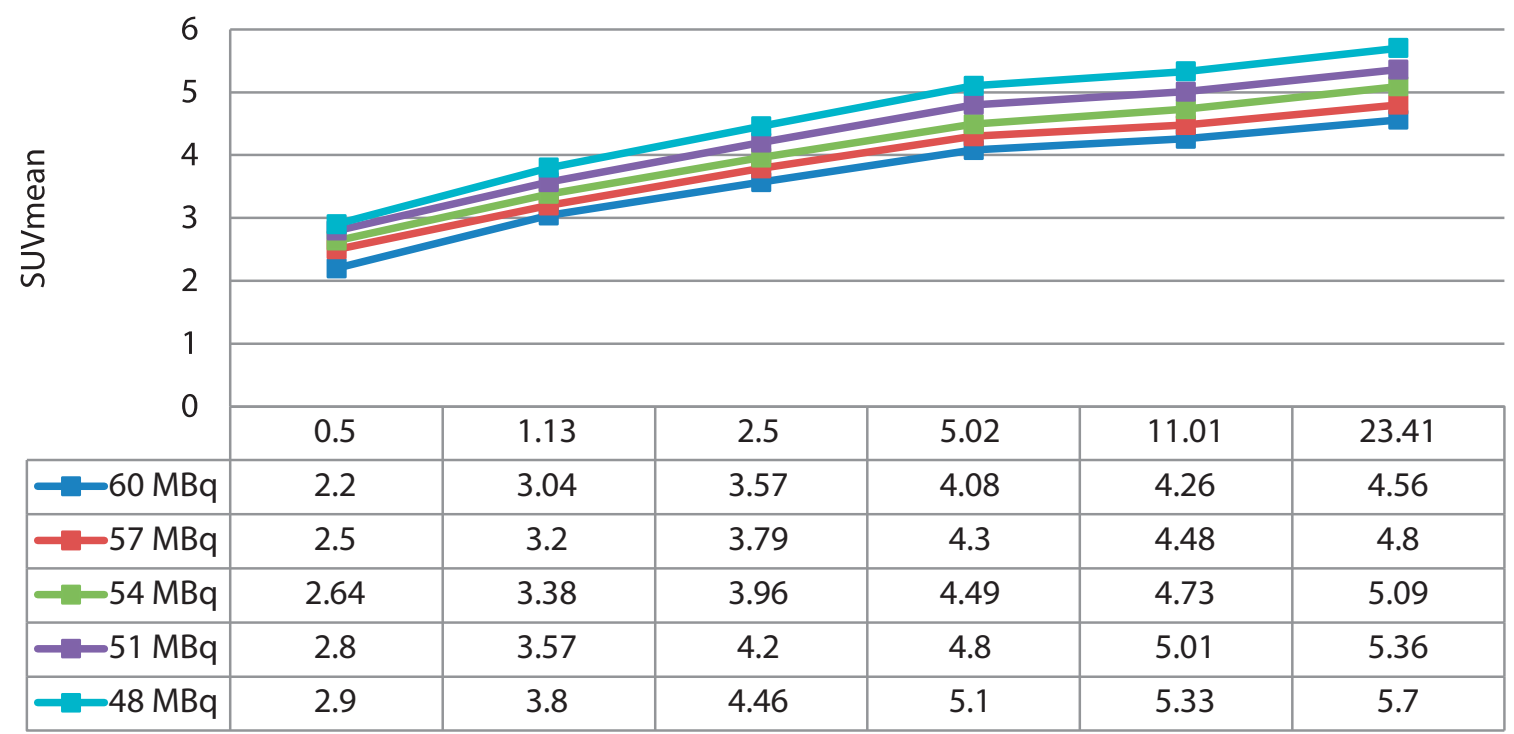

Image 8: SUVmean values of different sphere volumes and different radiopharmaceutical activities. The curves illustrate the SUVmean value fluctuations at different radiopharmaceutical activities.

applied manually. Using an automatic applicator can eliminate these issues in most cases. If RP is applied paravenously, the quantitative assessment of SUV is not objective. It is, however, still possible and a visual assessment of the PET/CT image is facilitated. The performed analysis confirmed that an incomplete application or inappropriately prepared activity can have a significant impact on the quantitative value of SUVmax and SUVmean, and matched the results published by other authors $(3,19)$.

PET/CT work includes doctors, medical physicists, registered nurses and graduate radiographers. Radiographers are responsible for a correctly performed examination, which also includes the correct entry of data in imaging protocol (RP applied activity, RP application time, patient's weight and height) and RP application.

Radiographers regularly conduct routine tests (daily and monthly quality control tests (QC)) on a PET/CT machine and applicator, and annual tests together with medical physicists.

\section{CONCLUSION}

Quantitative assessment of SUVmax and SUVmean is an important tool in oncology imaging assessment. The analyses showed that parameters, which include incorrect time between the RP application and imaging time, incomplete application or incorrectly measured RP activity as well as incorrect or incorrectly entered body weight of the patient into imaging protocol, can have a significant impact and alter the quantitative assessment of SUVmax and SUVmean. Since a radiographer bears a great responsibility when performing imaging, they must be aware of potential errors that can lead to an incorrect quantitative assessment of SUVmax and SUVmean in the PET/CT examination.

\section{REFERENCES}

1. Juweid ME, Stroobants $S$, Hoekstra OS, et al. Use of positron emission tomography for response assessment of lymphoma: consensus of the Imaging Subcommittee of International Harmonization Project in Lymphoma. J Clin Oncol. 2007 Feb 10;25(5):571-578.

2. Larson SM, Schwartz LH. 18F-FDG PET as a candidate for "qualified biomarker": functional assessment of treatment response in oncology. J Nucl Med. 2006 Jun;47(6):901903.

3. Weber WA. Use of PET for monitoring cancer therapy and for predicting outcome. J Nucl Med. 2005 Jun;46(6):983995.

4. Cheson BD, Pfistner B, Juweid ME, et al. Revised response criteria for malignant lymphoma. J Clin Oncol. 2007 Feb 10;25(5):579-586.

5. Weber WA. Chaperoning drug development with PET. J Nucl Med. 2006 May;47(5):735-737.

6. Sadato N, Tsuchida T, Nakamura S, et al. Non-invasive estimation of the net influx constant using the standardized uptake value for quantification of FDG uptake of tumours. Eur J Nucl Med. 1998 Jun;25(6):559564.

7. Graham MM, Peterson LM, Hayward RM. Comparison of simplified quantitative analyses of FDG uptake. Nucl Med Biol. 2000 Oct;27(7):647-655.

8. Stahl A, Ott K, Schwaiger M, Weber WA. Comparison of different SUV-based methods for monitoring cytotoxic therapy with FDG PET. Eur J Nucl Med Mol Imaging. 2004 Nov;31(11):1471-1479. 
9. Kim CK, Gupta NC. Dependency of standardized uptake values of fluorine-18 fluorodeoxyglucose on body size: comparison of body surface area correction and lean body mass correction. Nucl Med Commun. 1996 Oct;17(10):890-894.

10. Zasadny KR, Wahl RL. Standardized uptake values of normal tissues at PET with 2-[fluorine-18]-fluoro-2-deoxyD-glucose: variations with body weight and a method for correction. Radiology. 1993;189:847-850.

11. Sugawara $Y$, Zasadny KR, Neuhoff AW, Wahl RL. Reevaluation of the standardized uptake value for FDG: variations with body weight and methods for correction. Radiology. 1999 Nov; 213(2):521-525.

12. Geworski L, Knoop BO, de Wit M, Ivancevic V, Bares R, Munz DL. Multicenter comparison of calibration and cross calibration of PET scanners. J Nucl Med. 2002 May(5);43:635-639.

13. Westerterp M, Pruim J, Oyen W, et al. Quantification of FDG PET studies using standardised uptake values in multi-centre trials: effects of image reconstruction, resolution and ROI definition parameters. Eur J Nucl Med Mol Imaging. 2007 Mar;34(3):392-404.

14. Hoekstra CJ, Hoekstra OS, Stroobants SG, et al. Methods to monitor response to chemotherapy in non-small cell lung cancer with 18F-FDG PET. J Nucl Med. 2002 Oct;43(10):1304-1309.
15. Tahari AK, Chien D, Azadi JR, Wahl RL. Optimum Lean Body Formulation for Correction of Standardized Uptake Value in PET Imaging. J Nucl Med. 2014 Sep;55(9):14814.

16. Du Bois D and Du Bois E. A formula to estimate the approximate surface area if height and weight be known. Arch Intern Med 1916;17:863-71.

17. Lammertsma AA, Hoekstra CJ, Giaccone G, Hoekstra OS. How should we analyse FDG PET studies for monitoring tumour response? Eur J Nucl Med Mol Imaging. 2006 Jul;33(suppl 1):16-21.

18. Young $H$, Baum $R$, Cremerius $U$, et al. Measurement of clinical and subclinical tumour response using [18F]-fluorodeoxyglucose and positron emission tomography: review and 1999 EORTC recommendations. European Organization for Research and Treatment of Cancer (EORTC) PET Study Group. Eur J Cancer. 1999 Dec;35(13):1773-1782.

19. Boellaard R, Oyen WJ, Hoekstra CJ, et al. The Netherlands protocol for standardisation and quantification of FDG whole body PET studies in multicentre trials. Eur J Nucl Med Mol Imaging. 2008 Dec;35(12):2320-2333. 